\title{
Equimodalidade e Hôs Epi To Poly no De Interpretatione 9
}

Ricardo Santos

In the first part of De Interpretatione 9, Aristotle introduces an argument for fatalism that he obviously does not subscribe to. Readers of the chapter wonder how Aristotle replies to that argument. In this paper I claim that the main basis of his reply is the principle of equimodality stated in 19a33 ("statements are true in the same way as the actual things are"). I defend that this principle should be interpreted in the most straightforward way, as saying that the modality with which any statement is true is the same as the modality with which the actual things referred to in the statement are what they are. This entails that something is (or will be) necessarily such and such only if the statement saying that it is (or will be) such and such is necessarily true. By applying this principle to Aristotle's distinction between two kinds of non-necessary things those that happen as chance has it and those that happen for the most part (hôs epi to poly) in one way rather than another -, one should conclude that, because these things are contingent, statements about them can only be contingently true.

\section{$\S 1$. Introdução}

O capítulo 9 do Da Interpretação (daqui em diante: Int. 9) é um dos textos mais estudados e comentados das obras de Aristóteles. Ele contém a primeira apresentação e discussão conhecida do problema dos futuros contingentes. Porém, a sua interpretação continua incerta, envolvida em grande controvérsia. O ponto principal do desacordo diz respeito à questão de saber qual é a solução proposta por Aristóteles para o problema. Uma interpretação dominante, muitas vezes chamada a interpretação tradicional, considera que a solução de Aristóteles consiste em negar o princípio da bivalência para evitar o fatalismo. Se fosse essa a solução, isso significaria que Aristóteles aceita que a bivalência (quer dizer, o princípio segundo o qual todos os enunciados declarativos são sempre ou verdadeiros ou falsos) implica o fatalismo (quer dizer, a tese segundo a qual nenhum facto é contingente ou, de maneira equivalente, que tudo o que é o caso é necessariamente o caso). ${ }^{1} \mathrm{~A}$ interpretação alternativa, a que chamarei interpretação

\footnotetext{
${ }^{1}$ Diferentemente do que fiz em trabalhos anteriores, prefiro agora chamar "fatalismo" a esta tese e reservar a designação "determinismo" para a tese de que tudo o que acontece é uma
} 
bivalente, e que perfilho, considera antes que Aristóteles mantém a sua adesão ao princípio da bivalência, mas não pensa que daí se possa inferir o fatalismo.

Centrar a discussão na aceitação ou rejeição do princípio da bivalência pode, no entanto, ser um pouco enganador. É bastante evidente que, no Int. 9, aquilo que Aristóteles tem principalmente em vista é, não a bivalência, mas a chamada regra dos pares contraditórios (daqui em diante: RPC), segundo a qual, dado qualquer par de declarações contraditórias (em que uma nega exactamente aquilo que a outra afirma), necessariamente uma delas é verdadeira e a outra é falsa. O capítulo 9 continua a discussão dessa regra, que foi iniciada no capítulo 7. Em particular, Aristóteles expõe, em duas versões, um argumento que toma a RPC como premissa e deriva o fatalismo como conclusão. A sua rejeição da conclusão fatalista é perfeitamente explícita e inequívoca. $\mathrm{O}$ que levanta dúvidas é a avaliação final que faz do argumento. Será, na sua perspectiva, um argumento válido com uma premissa falsa ou um argumento com premissas verdadeiras mas inválido? Nos capítulos 7 e 8, Aristóteles admitiu duas excepções à RPC - a respeito das declarações indefinidas e a respeito de declarações que envolvem nomes que significam mais do que uma coisa. Vários comentadores consideram que, no capítulo 9, Aristóteles abre uma nova excepção à RPC, desta vez a respeito das declarações singulares sobre o futuro. ${ }^{2}$ Discordo dessa interpretação. Penso que Aristóteles mantém no Int. 9 a sua habitual adesão à bivalência ${ }^{3}$ e que, por isso, dado um par de declarações contraditórias acerca de qualquer futuro contingente, sustenta que cada uma dessas declarações é, isoladamente, ou verdadeira ou falsa - e que, tomadas em conjunto, têm de ser uma verdadeira e a outra falsa, dado que não é possível que sejam ambas verdadeiras, nem é possível que sejam ambas falsas. ${ }^{4}$

O facto de a interpretação da solução de Aristóteles ser tão incerta e objecto de tanta disputa tem uma explicação. O Int. 9 tem duas partes bem distintas. Na primeira, Aristóteles expõe o argumento fatalista, procurando adoptar o ponto de vista dos próprios fatalistas (chegando mesmo a incluir, em 18b17-25, uma crítica a uma possível réplica ao

consequência necessária das leis da natureza e do estado do mundo no passado remoto. Sigo assim a terminologia de van Inwagen (1983), ainda que a minha definição de fatalismo seja diferente da dele.

${ }^{2}$ É o caso, entre outros, de Whitaker (1996, p. 109) e de Jones (2010, pp. 29-30).

${ }^{3}$ Entre os defensores de que Aristóteles mantém a bivalência no Int. 9 contam-se Anscombe (1956), Hintikka (1973), G. Fine (1984), Judson (1988), Bäck (1992) e Whitaker (1996).

${ }^{4}$ As opções "ambas verdadeiras" e "ambas falsas" são consideradas e afastadas em 18a38-39 e $18 \mathrm{~b} 17-18$, respectivamente. 
argumento). Na segunda parte, a partir de 19a7, Aristóteles fala por si mesmo, dizendo aquilo que pensa - entre outras coisas, que o fatalismo é falso e que é óbvio que há muitas coisas contingentes e que as nossas deliberações e acções têm um poder causal decisivo sobre como o futuro irá ser - e sublinhando aquilo que deverá ter escapado ao autor do argumento fatalista. Mas há uma coisa que Aristóteles não faz na segunda parte: ele não regressa ao argumento para dizer onde é que estão as suas falhas ou para identificar os elementos do argumento que rejeita. Aristóteles terá provavelmente julgado que essa identificação poderia facilmente inferir-se a partir das coisas que diz, mas o facto é que deixou esse trabalho para o leitor. Pela maneira como compreendo aquilo que Aristóteles diz na segunda parte, penso que ele dá aí suficientes indicações de que o que deve ser rejeitado no argumento fatalista é a inferência da verdade sobre o futuro para a necessidade desse futuro. Esta inferência é um elemento central do argumento. $\mathrm{Na}$ exposição da primeira parte, encontramo-la enunciada várias vezes, sempre sem justificação, como algo que seria evidente. A sua formulação mais clara é talvez a que está em 19a4-5: "aquilo que alguém disse com verdade que iria ser não pode não vir a ser". Na perspectiva de Aristóteles, tal como a entendo, esta inferência não é correcta e, por isso, o fatalismo não se segue da existência de uma verdade sobre o futuro. A conclusão fatalista seguir-se-ia se a verdade sobre o futuro fosse ela própria uma verdade necessária. Mas, a respeito dos futuros contingentes, a verdade anterior não é uma verdade necessária. Sobre cada acontecimento futuro contingente, tem de haver (desde sempre) uma verdade - isso decorre da própria RPC -, mas não há um enunciado que tenha de ser verdadeiro. Aristóteles parece pensar que o fatalista confundiu esta diferença de âmbito da necessidade.

No presente ensaio, irei em grande medida pressupor simplesmente que esta interpretação da solução proposta por Aristóteles é correcta. A defesa completa desta interpretação ficará para outra ocasião. Os objectivos do ensaio são mais circunscritos, e são dois. Em primeiro lugar, pretendo estudar a presença no Int. 9 da conhecida distinção aristotélica entre dois tipos de coisas contingentes - aquelas que acontecem de maneira casual ou sem regra e aquelas que acontecem na maior parte dos casos de uma certa maneira ou que exibem uma regularidade - e mostrar a sua importância na sequência argumentativa do texto. Em segundo lugar, pretendo analisar o princípio de equimodalidade formulado em 19a33 e propor que, mais do que as diferenças de âmbito da necessidade, mas claramente associado a elas, é ele a base principal da resposta de Aristóteles ao argumento fatalista. Subjacente a estes objectivos está a convicção de que 
uma melhor compreensão destes dois aspectos importantes reforçará em grande medida a plausibilidade da interpretação bivalente do Int. 9 .

\section{§2. O Argumento Fatalista}

Na primeira parte do Int. 9, Aristóteles expõe o argumento fatalista. Ainda que eu não vá debruçar-me sobre os pormenores dessa exposição, será útil começar por fazer uma apresentação resumida do argumento. O ponto de partida é uma aplicação da RPC: "se uma pessoa disser que uma certa coisa irá ser e outra pessoa negar isso mesmo, é evidente que necessariamente uma delas está a dizer a verdade" (18a35-37). Aristóteles imagina duas pessoas que, agora, fazem declarações contraditórias acerca do futuro. Provavelmente, devemos supor (à luz de 18a33) que essas declarações são singulares, quer dizer, são declarações acerca de algo individual. Por exemplo, poderiam ser acerca do manto que uma delas tem vestido. Suponhamos então que uma pessoa diz "Este manto será cortado" e a outra diz o oposto, "Este manto não será cortado". ${ }^{5}$ De acordo com a RPC, uma destas declarações $e ́$ verdadeira ${ }^{6}$, mesmo que ninguém saiba qual delas é. $\mathrm{O}$ primeiro passo do argumento fatalista consiste precisamente em estabelecer esta existência de uma verdade (mesmo que desconhecida) acerca do futuro. Mais adiante, Aristóteles sublinhará que a existência desta verdade é independente do facto de as declarações contraditórias terem sido feitas (18b36-37: "não faz nenhuma diferença se alguém fez ou não fez as declarações contraditórias"). A observação condicional de que, se as declarações contraditórias fossem feitas, uma delas seria verdadeira, é suficiente para estabelecer que há uma verdade acerca do futuro do manto - a qual pode ser afirmada ou não afirmada, acreditada ou não acreditada, conhecida ou não conhecida. Além disso, e embora este aspecto não seja o mais importante, assume-se ainda que essa verdade existe desde sempre. Pois se imaginarmos as declarações a serem feitas, não agora, mas há dez mil anos (18b33-34), ou noutro momento qualquer do passado (19a1), o resultado é o mesmo. O segundo passo do argumento usa a existência dessa verdade acerca do futuro para a partir dela inferir que aquilo que irá ser irá ser necessariamente. No nosso

\footnotetext{
${ }^{5}$ Trata-se do exemplo usado por Aristóteles em 19a12-16.

${ }^{6} \mathrm{O}$ verbo em "é verdadeira" deve ser entendido de maneira temporal, como sinónimo de "é agora". Como é bem sabido, Aristóteles considerava que um mesmo enunciado declarativo pode ser verdadeiro nuns momentos e falso noutros momentos. Cf. Cat. 4a36-b1; Crivelli 2004, pp. 183-184.
} 
exemplo, se for verdadeira a afirmação, então o manto irá necessariamente ser cortado (isto é, não poderá deixar de o ser); se, pelo contrário, for verdadeira a negação, então o manto necessariamente não será cortado (isto é, não poderá sê-lo). Uma vez que está garantido pela RPC que uma das declarações é verdadeira (pois "é necessário que a afirmação ou a negação seja verdadeira", 18b4, repetido em 18b7-8), o que quer que aconteça ao manto acontecerá por necessidade. Por fim, dado que o exemplo foi arbitrariamente escolhido, a consequência pode ser generalizada, atingindo-se então a conclusão fatalista: "Portanto, todas as coisas futuras virão a ser necessariamente. E, por isso, nada irá ser de maneira casual (hopoter etychen) ou por acaso (apo tychês); pois, se fosse por acaso, não seria por necessidade" (18b14-16).

Depois de apresentar o argumento, Aristóteles aponta as consequências "absurdas" (18b26) que a conclusão fatalista teria, as quais se revelam especialmente graves no domínio da acção humana: "não seria preciso deliberarmos nem esforçarmonos - pensando que, se fizermos isto, será assim, mas se não fizermos, não será" (18b3133). Normalmente, antes de tomarmos uma decisão, representamos mentalmente um certo curso de acção e reflectimos sobre se devemos ou não realizá-lo, no pressuposto de que tanto o podemos fazer como podemos não o fazer. O famoso exemplo da batalha naval, dado por Aristóteles, enquadra-se nesta categoria. Uma batalha naval é normalmente precedida de uma cuidadosa ponderação. É assim bastante natural imaginarmos um almirante em reunião com os seus conselheiros, reflectindo sobre se deve ou não, amanhã, atacar as forças inimigas com os seus barcos, originando uma batalha. Neste tipo de ponderação, tentamos sempre antecipar as consequências de cada uma das possibilidades em aberto, para escolhermos a melhor opção possível. Porém, se o fatalista tivesse razão, este exercício deliberativo não teria nenhum sentido, uma vez que não serviria para nada. Na realidade, embora nós, os agentes, normalmente não tenhamos conhecimento dela, há desde sempre uma verdade acerca daquilo que iremos fazer e, por isso, agiremos necessariamente de acordo com essa verdade anterior. Ou seja, em cada ocasião, a acção que realizamos seria a única que podíamos realizar e não podíamos abster-nos de a realizar. Não existiriam possibilidades alternativas e tudo o que acontece, incluindo aquilo que nós próprios fazemos, seria absolutamente inevitável. Jan Łukasiewicz descreveu assim a visão fatalista do mundo: "Somos apenas marionetas no drama 
universal. Não nos resta fazer mais do que assistir ao espectáculo e esperar pacientemente pelo seu fim". ${ }^{7}$

\section{§3. Dois Tipos de Coisas Contingentes}

Em 19a7, Aristóteles inicia a sua crítica ao que antes esteve a expor. O fatalismo, na sua perspectiva, é falso. Como justificação para negá-lo, começa por apontar o facto de nós, enquanto agentes, sermos iniciadores de muitos acontecimentos futuros - os quais não ocorreriam se não fosse a nossa decisão e a nossa acção. Depois diz que, mesmo fora do campo da acção humana, no mundo em geral, há abundante evidência de contingência. Alguns seres “estão sempre em acto" (19a9) e, por isso, são necessariamente e sempre da mesma maneira (como é o caso dos astros). ${ }^{8}$ Mas, nos restantes seres, "ambas as coisas são possíveis: tanto o ser como o não ser e, por conseguinte, tanto o vir a ser como o não vir a ser" (19a10-11). Neste ponto do texto, quando chama a atenção para a grande abundância de coisas contingentes que há no mundo, Aristóteles introduz uma distinção entre dois tipos de coisas contingentes. A passagem é a seguinte:

T1

É claro, então, que nem tudo é ou vem a ser por necessidade: umas coisas são de maneira casual (e da afirmação e da negação nenhuma é mais verdadeira do que a outra), enquanto outras são na maior parte dos casos mais de uma maneira do que de outra, mas ainda assim é possível que venham a ser antes da outra maneira. $(19 \mathrm{a} 18-22)^{9}$

Aristóteles expressa em T1 a sua própria perspectiva sobre o assunto. Há coisas necessárias, mas nem tudo é necessário. Há também coisas contingentes e estas são de dois tipos. Por um lado, há coisas que "são de maneira casual" (ta men hopoter' etyche); por outro, há coisas que "são na maior parte dos casos mais de uma maneira do que de outra" (ta de mallon men kai hôs epi to poly thateron). Esta distinção é bastante importante no pensamento aristotélico, justificando-se por isso que nos detenhamos sobre ela.

\footnotetext{
${ }^{7}$ Łukasiewicz 1970, p. 113.

${ }^{8}$ A identificação daquilo que é em acto com aquilo que é necessariamente é feita explicitamente em Int. 13, 23a21-22.

${ }^{9}$ Em todo o artigo, uso as traduções das Categorias e do Da Interpretação que fiz em Santos (2016, pp. 59-117 e 169-212). As traduções dos restantes textos que cito no artigo são também da minha responsabilidade.
} 
Em geral, na sua maneira de conceber o mundo, Aristóteles sustenta uma classificação tripartida segundo a qual existem (i) coisas que acontecem necessariamente e sempre da mesma maneira, (ii) coisas que acontecem na maioria dos casos de uma certa maneira e (iii) coisas que acontecem por acaso ou acidentalmente, isto é, sem regra. $\mathrm{Na}$ Metafísica E2, capítulo dedicado à análise do ser acidental, esta tripartição está bem presente, explicada com o auxílio de vários exemplos. A dado passo, em 1027a9-10, Aristóteles afirma que a maior parte das coisas pertencem à segunda categoria, daquelas que acontecem "na maioria dos casos" (hôs epi to poly), quer dizer, nem por necessidade nem por acaso. Como exemplo, aponta o facto de que "o hidromel ${ }^{10}$ é benéfico para um doente com febre" (1027a23-24).

Esta noção de algo que acontece na maioria dos casos é extremamente importante para a concepção que Aristóteles tem das ciências naturais. ${ }^{11}$ Em Partes dos Animais III 2, ele diz que "no estudo da natureza, o que devemos considerar é aquilo que acontece repetidamente (ta polla); pois o que é natural é aquilo que acontece ou em todos os casos ou na maioria dos casos" (663b27-29). É a procura de regularidades naturais que deve guiar a pesquisa científica. Muitas destas regularidades não são, estritamente falando, leis universais e necessárias. Pelo contrário, têm excepções. Nas obras de biologia, a noção de uma regularidade natural que admite excepções ocorre abundantemente. Aristóteles encara estas excepções como coisas que, embora possíveis, são "contrárias à natureza" (para physin). As monstruosidades incluem-se nesta categoria e aquilo que Aristóteles diz a seu respeito torna claro que, quando chamamos algo "natural", isso pode ser entendido de duas maneiras (como estando a qualificar ou algo que é "eterno e necessário" ou algo que ocorre "na maior parte dos casos"), mas, quando dizemos que uma coisa é "contrária à natureza", só podemos estar a tomar a natureza e o natural da segunda maneira. A seguinte passagem de Geração dos Animais IV 4 di-lo muito explicitamente: "nada pode acontecer contrariamente à natureza considerada como eterna e necessária, mas tal só ocorre quando as coisas acontecem de uma maneira na maior parte dos casos, mas podem também acontecer de outra maneira" (770b11-13). ${ }^{12}$

As coisas que acontecem fortuitamente, por acaso ou sem regra não são, para Aristóteles, as únicas coisas contingentes. Aquilo que acontece na maioria dos casos, e

\footnotetext{
${ }^{10}$ Uma mistura de água e mel.

${ }^{11}$ Veja-se, sobre isso, Mignucci (1981) e Judson (1991).

${ }^{12}$ Cf. também GA 777a20-22.
} 
que é natural nesse sentido, também é contingente: se um objecto é de um tipo tal que cai sob uma certa regularidade conhecida, pode sempre acontecer que as nossas expectativas a seu respeito se vejam frustradas e que ele se comporte ou que mostre ser de maneira contrária àquela que é geralmente exibida por objectos desse tipo. Há uma importante passagem nos Primeiros Analíticos I 13 em que estas duas espécies de contingência são claramente distinguidas:

$\mathrm{T} 2$

Digamos ainda que o ser possível (to endechesthai) se diz de duas maneiras. De uma maneira, diz-se daquilo que acontece na maior parte dos casos, quando o necessário tem hiatos, como um homem tornar-se grisalho ou crescer ou definhar ou, em geral, aquilo que pertence por natureza [...]. De outra maneira, diz-se daquilo que é indeterminado (to aoriston), ou seja, daquilo que pode ser tanto assim como não assim, como um animal andar ou ocorrer um tremor de terra quando ele está a andar ou, em geral, aquilo que acontece por acaso, pois isso não é por natureza mais desta maneira do que da maneira contrária. (APr. 32b4-13)

Como já foi apontado por vários comentadores ${ }^{13}$, em T2, Aristóteles usa endechesthai, não com o sentido mais geral (e para nós mais próprio) de ser possível, mas com o sentido especial de ser contingente. A prova disso é que, no mesmo capítulo, por mais de uma vez, ele afirma que "o possível não é necessário" (32a36), tese que só é correcta se nela entendermos "possível" (endechomenon) como querendo dizer contingente. Aristóteles, no entanto, dá-se conta de que o termo "possível” nem sempre é usado desta maneira (como sinónimo de "contingente") ${ }^{14}$ e, por isso, observa em 32a2021 que "o necessário é chamado possível num sentido diferente".

T2 propõe então uma distinção entre dois tipos de contingência. O primeiro tipo é o das coisas que acontecem apenas "na maior parte dos casos" e que se identifica com uma noção de "natural". E o segundo tipo é o das coisas fortuitas, que não seguem nenhuma regularidade e que aqui Aristóteles qualifica como "indeterminadas". Os exemplos são eloquentes. É natural que um homem se torne grisalho com a idade e é isso que verificamos na maior parte dos homens, mas nem sempre é assim. Por isso, estritamente falando, não se trata de algo que seja necessário. Por outro lado, se observamos um cão, é possível que nesse momento ele esteja a andar, mas é igualmente possível que ele não esteja a andar, e não há a esse respeito nenhuma regularidade ou

\footnotetext{
${ }^{13}$ Cf. van Rijen 1989, p. 19 e Striker 2009, p. 127.

${ }^{14}$ Parece-me muito provável que, quando no Int. 9, em 19a16-18, após analisar o exemplo do manto, Aristóteles generaliza a conclusão dessa análise para as coisas "que vêm a ser e de que falamos de acordo com este tipo de possibilidade", ele esteja a referir-se precisamente ao uso de "possibilidade" como sinónimo de "contingência".
} 
tendência natural. É importante sublinhar que, quando propõe esta distinção, Aristóteles está a classificar tipos de acontecimentos, e não acontecimentos singulares. Acerca de um acontecimento singular, seja ele qual for, não faz sentido dizer que ele ocorre na maior parte dos casos. Mas se um dado acontecimento singular, que ocorre num momento específico, exemplifica um certo tipo de acontecimento, aí sim, podemos perguntar, a respeito desse tipo de acontecimento, se é ou não algo que ocorre na maior parte dos casos.

Regressemos, então, ao Int. 9 e à análise da passagem T1. À luz do que acabávamos de dizer sobre a classificação tripartida, familiar no pensamento de Aristóteles, entre o necessário, o regular e o fortuito, penso que é inegável que é a essa mesma classificação que ele se refere em T1. O fatalista pretenderia defender que tudo é necessário e Aristóteles opõe-se-lhe dizendo que há dois tipos de acontecimentos que não são necessários - os acontecimentos fortuitos e os acontecimentos regulares. Penso que a presença desta distinção no Int. 9 e o papel que ela desempenha na discussão aristotélica do argumento fatalista não tem sido suficientemente tida em conta e valorizada pelos comentadores. ${ }^{15}$ É bastante notório que, na primeira parte do capítulo, a exposição inicial do argumento privilegiou uma oposição simples entre a necessidade e o acaso. Por exemplo, em 18b5-7, quando a consequência fatalista é formulada, diz-se: "Por consequência, nada é ou vem a ser, ou será ou não será, por acaso ou de maneira casual, mas sim tudo por necessidade e não de maneira casual." E, sete linhas adiante, em 18b1416, repete a consequência: "Portanto, todas as coisas futuras virão a ser necessariamente. E, por isso, nada irá ser de maneira casual ou por acaso; pois, se fosse por acaso, não seria por necessidade.” O argumento fatalista foi inicialmente encarado, é seguro dizê-lo, como uma ameaça à categoria do fortuito, que excluiria aquelas coisas que acontecem sem regra e em que as duas possibilidades contrárias estão perfeitamente a par. Isso é também confirmado pelos exemplos escolhidos e considerados ao longo do capítulo, os quais parecem pertencer todos a esta categoria. É assim claramente com o exemplo do manto (em 19a12-16) e com o exemplo da batalha naval de amanhã (em 18b24-25 e 19a29-32). Mas também parece ser esse o caso do exemplo bastante esquemático ou indefinido do "ser branco" (em 18a39-b3 e 18b9-10) (pelo menos se o lermos à luz da afirmação, na Metafísica 1026b35-36, de que "acidentalmente sucede que o homem é branco (não o é,

\footnotetext{
${ }^{15}$ Mas veja-se, em sentido contrário, G. Fine 1984, p. 44, n. 28.
} 
com efeito, nem sempre nem a maior parte das vezes)"). E também com o quase-exemplo, em 18b32-36, da decisão não especificada de "fazer isto".

Se esta leitura está correcta, então há algo digno de nota que acontece na passagem $\mathrm{T} 1$, que é o surgimento na discussão de um tipo de contingência que até aí quase ${ }^{16}$ não tinha sido considerado - a contingência das coisas regulares, que acontecem na maior parte dos casos de uma maneira particular. Na perspectiva de Aristóteles, a existência, que ele toma como evidente, de coisas que acontecem dessa maneira é também prova de que o fatalismo é falso. Por regra, o hidromel faz baixar a febre, mas nem sempre. Portanto, quando um doente febril toma hidromel, temos uma expectativa legítima de que a sua febre vá baixar, pois é isso que acontece na maioria dos casos. Porém, mesmo num caso assim, em que existe uma regularidade natural, ambos os resultados são possíveis e, por isso, qualquer que seja o resultado que se venha a verificar, ele será contingente. No exemplo do manto, em que o desfecho depende inteiramente de uma decisão livre individual, a contingência será porventura ainda mais evidente. Mas ela está também presente nos casos em que a própria natureza fixa uma regularidade ou tendência.

Outro aspecto digno de nota na passagem T1 é a maneira como os casos fortuitos são caracterizados. Normalmente, Aristóteles refere-se a esses casos dizendo que eles acontecem por acaso, ou “de maneira casual”, e que neles o vir a ser e o não vir a ser são ambos igualmente possíveis. Mas, em T1, caracteriza tais casos dizendo que neles se verifica o seguinte: "da afirmação e da negação nenhuma é mais verdadeira do que a outra" (19a19-20). Esta observação é muito curiosa, porque ao fazê-la Aristóteles procede a uma espécie de ascensão semântica, em que tenta caracterizar as coisas fortuitas pela maneira como a RPC se lhes aplica. Tomada a frase à letra, pareceria que Aristóteles estaria a admitir a existência de graus de verdade, dizendo que, do par contraditório, nem a afirmação é mais verdadeira do que a negação, nem a negação é mais verdadeira do que a afirmação. Dado que Aristóteles não considera que a verdade admite diferentes graus, devemos procurar uma interpretação alternativa, não literal. A interpretação mais plausível parece-me ser a que toma " $\alpha$ é mais verdadeira do que $\beta$ " como uma maneira menos cuidada de dizer " $\alpha$ é verdadeira em mais casos do que $\beta$ " (ou "os casos em que $\alpha$ é verdadeira são mais numerosos do que os casos em que $\beta$ é verdadeira"). Ora, esta é uma descrição que se aplica bem às coisas regulares. Como elas acontecem de uma certa

\footnotetext{
${ }^{16}$ Digo "quase", porque podemos talvez ver uma breve alusão implícita ao hôs epi to poly em
} $18 \mathrm{~b} 8-9$. 
maneira na maior parte dos casos, podemos dizer, como Aristóteles faz em 19a20-21, que elas são "mais de uma maneira do que de outra". Por exemplo, é mais frequente o hidromel fazer baixar a febre do que acontecer o contrário. Nessa medida, dado um par de declarações contraditórias a esse respeito, como por exemplo "A ingestão de hidromel fará baixar a febre" e "A ingestão de hidromel não fará baixar a febre", podemos dizer que a afirmação é verdadeira em mais casos do que a negação, ou, numa formulação menos rigorosa, que a afirmação é mais verdadeira do que a negação. Em suma, nesta caracterização semântica, Aristóteles está especialmente interessado na diferença entre as coisas fortuitas e as coisas regulares quanto ao modo como a RPC se lhes aplica. Mas parece evidente, e este ponto é crucial, que ele pressupõe que a RPC se aplica em ambos os casos. Ou seja, quer em casos como o do manto, quer em casos como o do hidromel, é necessário que ou a afirmação ou a negação seja verdadeira (e que, sendo uma delas verdadeira, a outra seja falsa); mas com esta diferença: nos casos como o do hidromel, uma delas é "mais verdadeira" do que a outra (no sentido já explicado), enquanto isso não acontece nos casos como o do manto. Não seria compreensível que Aristóteles dissesse que a RPC se aplica às coisas fortuitas de maneira diferente daquela como se aplica às coisas regulares, se ele pensasse que a RPC não se lhes aplica. A presença desta pressuposição em T1, que é claramente uma passagem em que Aristóteles já está a expressar a sua própria perspectiva sobre as coisas (diferentemente do que acontecia nas secções anteriores, dedicadas antes à exposição de um argumento que ele não subscreve $)^{17}$, constitui uma forte evidência contra a interpretação tradicional do Int. 9.

\footnotetext{
${ }^{17} \mathrm{O}$ facto de, na primeira parte do capítulo, Aristóteles estar a expor um argumento que não subscreve nem sempre é devidamente tido em conta. Jones (2010, pp. 51-54), por exemplo, faz uma estranha leitura dessa primeira parte. Entre 18a34 e 19a6, encontra três argumentos que têm em comum o facto de tomarem a RPC como premissa e derivarem uma conclusão absurda, e considera por isso que esses argumentos mostram que a RPC é falsa (quando aplicada a declarações acerca do futuro). A partir daí, a tarefa de Aristóteles, na segunda parte do capítulo, seria explicar porque é que a RPC é falsa (quando aplicada a tais declarações). Esta leitura é de legitimidade muito duvidosa. De facto, na primeira parte, Aristóteles identifica a RPC como premissa; e, de facto, o argumento deriva uma conclusão absurda a partir dessa premissa. Mas isso só seria uma maneira de Aristóteles mostrar que a RPC é falsa se o argumento fosse um argumento proposto por Aristóteles, o que claramente não é o caso. O mesmo se deverá dizer da alegação, feita por Jones, de que "it is plain from the first half of chapter 9 that Aristotle is committed to denying [the principle of bivalence]" (p. 57, a ênfase é minha).
} 


\section{§4. A Equimodalidade}

Depois de, em T1, negar que tudo seja necessário e introduzir a distinção entre os dois tipos de coisas contingentes, a crítica de Aristóteles ao argumento fatalista prossegue com uma passagem (19a23-32) em que o assunto principal são as diferenças de âmbito a que é preciso estar atento quando se diz que algo é necessário. A minha explicação (inevitavelmente conjectural) para a introdução deste assunto neste ponto do texto é a de que, embora acabe de negar a necessidade universal defendida pelo fatalista, Aristóteles dá-se conta de que há uma necessidade que ele continua a querer afirmar, que é a necessidade contida na própria RPC: dado um par de declarações contraditórias, é necessário que uma delas seja verdadeira e a outra seja falsa. ${ }^{18}$ Esta afirmação de necessidade tem de ser cuidadosamente entendida.

Há vários textos de Aristóteles que testemunham que ele dava bastante atenção às possíveis ambiguidades de âmbito no uso das modalidades. Nas Refutações Sofísticas, por exemplo, em 166a23-30, esclarece que, quando se diz que alguém pode caminhar quando está sentado, ou que pode escrever quando não está a escrever, o significado do que é dito varia consoante se dê âmbito longo ou âmbito curto à possibilidade. Uma coisa é dizer, acerca de uma pessoa que está sentada, que ela pode caminhar; outra coisa é dizer, acerca dessa pessoa, que ela tem o poder de caminhar-quando-sentada. De modo semelhante, é absurdo dizer que alguém pode escrever-quando-não-escreve, mas é perfeitamente aceitável dizer, de uma pessoa que não está a escrever, que é possível que ela escreva19. Aristóteles não dispõe dos termos "âmbito longo" e "âmbito curto" para descrever a diferença em causa, mas usa em vez deles os verbos "combinar" e "dividir", exactamente para o mesmo efeito ${ }^{20}$. Quando se atribui a possibilidade à conjunção sentado-e-caminhando, está-se a "combinar"; quando se atribui a possibilidade apenas ao segundo membro da conjunção, está-se a "dividir". Note-se que é precisamente este mesmo verbo, “dividir”, que é também usado no Int. 9, em 19a29. Aí, Aristóteles lida com um exemplo mais complexo, em que a lei do terceiro excluído é aplicada a

\footnotetext{
${ }^{18}$ Cf. 17b27, 18a26-27, 18a28-29 e 18a31-32.

19 Veja-se também Cael. 281b2-14, onde são dados exemplos semelhantes. Outro exemplo significativo ocorre em APr. I 10, quando Aristóteles esclarece dois sentidos diferentes em que pode ser tomada a afirmação de que "Se a premissa positiva é necessária, a conclusão não será necessária" (30b18-19). Cf. Striker 2009, p. 120.
}

${ }^{20}$ Cf. Crivelli 2004, p. 213. 
acontecimentos futuros: "necessariamente, amanhã vai haver ou não vai haver uma batalha naval" (19a30). A instrução dada é a oposta: enquanto no exemplo das Refutações Sofísticas não se devia "combinar", neste exemplo, pelo contrário, não se deve "dividir" e dizer que ou é necessário que amanhã haja uma batalha ou é necessário que amanhã não haja nenhuma batalha.

Munidos destes esclarecimentos prévios acerca das possíveis e importantes diferenças de âmbito da necessidade, estamos em condições de abordar o assunto principal: Como deve ser entendida a afirmação de necessidade contida na RPC?

A necessidade defendida pelo fatalista seria uma necessidade das próprias coisas, um modo de elas terem de ser exactamente como são. Em contraste, a necessidade agora em causa diz respeito aos enunciados declarativos e à sua verdade ou falsidade. A discussão envolve obviamente dois planos distintos - o plano das coisas e o plano dos enunciados. A relação entre os dois planos é aqui fundamental, dado que o argumento sob escrutínio pretende usar a RPC (situada no plano dos enunciados) para derivar a conclusão fatalista (situada no plano das coisas). Além disso, as modalidades estão presentes em ambos os planos: no plano das coisas, porque se discute se tudo é necessário ou se há também coisas contingentes; no plano dos enunciados, porque a RPC diz que é necessário que uma das declarações contraditórias seja verdadeira. É então, considerando os dois planos e as respectivas modalidades, que Aristóteles formula este princípio fundamental:

$\mathrm{T} 3$

[...] os enunciados são verdadeiros da mesma maneira como as próprias coisas são [...]. (19a33: homoiôs hoi logoi alêtheis hôsper ta pragmata)

Penso que esta é a frase mais mal compreendida de todo o Int. 9. Alguns comentadores não notam sequer a sua presença. Daqueles que a notam, muitos tomamna simplesmente como expressão da perspectiva realista que Aristóteles tem acerca da verdade (ou até como sinal da sua adesão a uma teoria correspondentista da verdade). Assim entendida, T3 quereria apenas dizer que a verdade depende da realidade, ou seja, que os enunciados são ou não são verdadeiros dependendo de se as coisas são ou não são como eles as representam. Evidentemente, sabemos bem que Aristóteles pensa assim ${ }^{21}$. Mas essa seria uma observação muito pouco relevante neste contexto. É sobre as modalidades, e em particular sobre a necessidade, sobre as suas diferenças de âmbito e

\footnotetext{
${ }^{21}$ Cf. Cat. 4b8-10, 14b18-22; Metaph. 1011b26-27, 1051b6-9.
} 
sobre como devemos entendê-la na RPC que aqui se está falar. Por isso, é muito mais plausível considerar que, em T3, Aristóteles se refere às diferentes maneiras como os enunciados podem ser verdadeiros. Há enunciados que são necessariamente verdadeiros e outros que, sendo verdadeiros, poderiam não o ser. Essas modalidades, diz Aristóteles em T3, estão alinhadas com as modalidades das próprias coisas. T3 expressa um princípio geral de equimodalidade, que poderíamos formular da seguinte maneira:

[E] $A$ é necessariamente $B$ se e somente se o enunciado que diz que $A$ é $B$ é necessariamente verdadeiro. $A$ é contingentemente $B$ se e somente se o enunciado que diz que $A$ é $B$ é contingentemente verdadeiro.

O princípio [E] é facilmente compreensível e facilmente exemplificável. Uma vez que a correspondência entre verdade e realidade é ela própria uma conexão necessária, qualquer situação contrafactual em que uma certa coisa fosse de maneira diferente do que é é também uma situação em que o enunciado que diz que essa coisa é dessa maneira (mantendo fixo o seu significado) não seria verdadeiro; e vice-versa. Quanto a exemplos, suponhamos que Sócrates está sentado e que eu declaro "Sócrates está sentado". A minha declaração é verdadeira. Mas Sócrates, embora esteja sentado, poderia não o estar e estar antes em pé ou a caminhar. De modo semelhante, a minha declaração, embora seja verdadeira, poderia ser falsa. A conexão verifica-se nos dois sentidos: se um certo facto é contingente, a declaração que diz que ele é o caso é apenas contingentemente verdadeira; e se uma declaração é contingentemente verdadeira, ou seja, se poderia ser falsa, então aquilo que ela diz que é o caso poderia não ser o caso. Consideremos agora um facto necessário. Por exemplo, o facto de que todo o homem é um animal. Como se trata de algo que não poderia não ser desse modo, então também é necessário que o enunciado "todo o homem é um animal" seja verdadeiro.

No De Caelo, Aristóteles escreve:

$\mathrm{T} 4$

O ser simplesmente falso e o ser simplesmente impossível não são a mesma coisa. Pois dizer que tu estás em pé quando não o estás, é falso, mas não impossível. De modo semelhante, dizer que o citarista está a cantar quando ele não está a cantar, é falso, mas não impossível. Dizer, porém, que tu estás ao mesmo tempo em pé e sentado, ou que a diagonal é comensurável, é não apenas falso, mas também impossível. Não é, portanto, a mesma coisa fazer uma suposição falsa e fazer uma impossível. (Cael. I 12, 281b8-14)

Nesta passagem, Aristóteles distingue dois tipos de enunciados declarativos falsos. O primeiro tipo, exemplificado pelos enunciados "tu estás em pé" (dito quando a pessoa em causa não está em pé) e "o citarista está a cantar" (dito quando o citarista em 
causa não está a cantar), consiste em enunciados que são falsos mas poderiam ser verdadeiros, ou seja, enunciados contingentemente falsos. O segundo tipo, exemplificado pelos enunciados "tu estás em pé e sentado" e "a diagonal (do quadrado) é comensurável (com os seus lados)", consiste em enunciados que são falsos e que não poderiam ser verdadeiros, ou seja, enunciados necessariamente falsos. Aristóteles usa em T4 uma terminologia diferente daquela nós usamos, pois apresenta a distinção como assentando na diferença entre dizer algo que é "falso, mas não impossível” e dizer algo que é "não apenas falso, mas também impossível”. Mas parece inegável que, com estas expressões, o que ele pretende fazer é precisamente a distinção entre falsidades contingentes e falsidades necessárias.

Se Aristóteles estava bem ciente da distinção entre falsidades contingentes e falsidades necessárias (como T4 mostra), então é natural que estivesse também ciente da distinção entre verdades contingentes e verdades necessárias. Dado isto, é então muito plausível considerar que esta distinção está pressuposta em T3 e que o propósito de Aristóteles em T3 é apontar que existe uma correspondência entre verdades contingentes e factos contingentes, por um lado, e entre verdades necessárias e factos necessários, por outro. A relevância desta correspondência para o escrutínio do argumento fatalista é fácil de antecipar, uma vez que se trata de um argumento que pretenderia concluir a necessidade de todos os factos a partir das verdades (anteriores) acerca deles. A questão que naturalmente surge ao espírito é: Qual é o estatuto modal dessas verdades? São verdades contingentes ou verdades necessárias? Veremos adiante como Aristóteles aborda esta questão nas linhas que continuam T3.

Antes disso, porém, examinemos se existem razões contra esta leitura de T3. Dorothea Frede considera a possibilidade de interpretar T3 como afirmação de uma “correspondência forte”, segundo a qual "a própria verdade é modificada de acordo com o modo do acontecimento" 22 , e rejeita-a por duas razões: por um lado, porque lhe parece que a alegada distinção entre verdade contingente e verdade necessária não é aplicada por Aristóteles nas linhas que se seguem a T3; por outro, porque Aristóteles nunca fez essa distinção. ${ }^{23}$ Frede afirma que não há nenhum texto de Aristóteles em que se possa

\footnotetext{
${ }^{22}$ Frede 1985, p. 75.

${ }^{23}$ Frede dirige a sua crítica principalmente a Anscombe que, no seu artigo de 1956, propôs uma interpretação do Int. 9 na qual a distinção entre verdade simples e verdade necessária desempenhava um papel central. Curiosamente, Anscombe não parece ter encontrado essa
} 
encontrar "uma distinção entre verdade e verdade necessária ou qualquer outra modalização do verdadeiro ou falso" e que é um erro supor que Aristóteles possuía essa distinção. ${ }^{24}$ Deixemos a resposta à primeira razão para depois, quando examinarmos a passagem em causa. Consideremos agora a segunda razão. A afirmação de Frede é muito audaz, mas penso que é falsa. Como já disse, parece-me inegável que a distinção entre falsidade contingente e falsidade necessária é o que Aristóteles pretende fazer em T4. Além disso, trata-se de uma distinção que ocorre igualmente noutros textos, ainda que Aristóteles tenda a expressá-la contrastando o "falso" com o "impossível" (compare-se Cael. 281b2-3 com Metaph. 1047b12-14 e APr. 34a25-29). A passagem da Metafísica $\Delta$ 12 em que são definidos “o possível e o impossível” (1019b23-32) merece ser destacada. Aí, Aristóteles define o "impossível” como "aquilo cujo contrário é necessariamente verdadeiro" (1019b23-24: hou to enantion ex anankês alêthes), de que dá como exemplo "a diagonal ser comensurável"; e define o "possível” como aquilo que ocorre "quando não é necessário o contrário ser falso" (1019b28-29: hotan mê anankaion êi to enantion pseudos einai), de que dá como exemplo "um homem estar sentado". Tanto as definições como os exemplos mostram claramente que Aristóteles chama aqui "impossível” ao necessariamente falso e chama aqui "possível" ao contingentemente verdadeiro. Frede reconhece que nesta passagem ocorrem diversas modalizações do verdadeiro e do falso, mas alega que "verdadeiro" e "falso" são aqui usados, não como predicados de declarações, mas como sinónimos de "ser" e "não ser". Esta leitura é extremamente implausível. Suponhamos que Aristóteles, quando dá o exemplo "um homem estar sentado", pretendia estar a ilustrar um facto contingente, e não uma declaração contingentemente verdadeira. A maneira natural de justificar que se trata de um facto contingente seria dizer algo como: "pois seria possível não estar sentado" ou "pois não é necessário que esteja sentado". Porém, em vez disso, a justificação que Aristóteles dá é esta: "pois o não estar sentado não é falso por necessidade” (1019b29-30: ou gar ex anankês to mê kathêsthai pseudos). Seria dificilmente compreensível que, nesta justificação, Aristóteles pretendesse usar "falso" como sinónimo de "não-ser". Se assim fosse, ele estaria a empregar uma negação tripla para expressar algo que poderia facilmente expressar com uma só negação. De facto, se o propósito fosse dizer que o facto

distinção em 19a33, linha que não comenta e que traduz como "propositions are true as the facts go" (1956, p. 7).

${ }^{24}$ Frede 1985 , pp. $47-48$. 
é contingente, bastar-lhe-ia dizer "pois o estar sentado não é por necessidade" ( ou gar ex anankês to kathêsthai). É muito mais natural que Aristóteles pretendesse aqui caracterizar a declaração contingentemente verdadeira como aquela cuja negação não é necessariamente falsa. Além disso, a semelhança entre esta passagem da Metafísica 1019b23-32 e a passagem do De Caelo 281b8-14 (=T4) é muito grande. Os exemplos são quase os mesmos e a distinção é exactamente do mesmo tipo. Ora, é inegável que, em T4, Aristóteles usa "falso" e "impossível" como predicados de declarações e de suposições (atente-se nas expressões "dizer que ... é falso", "dizer que ... é impossível", "fazer uma suposição falsa"). O mais provável é, portanto, que na Metafísica 1019b23-32 use também "possível”, "impossível", "verdadeiro" e "falso" como predicados de declarações e suposições. Assim sendo, devemos concluir que Aristóteles possuía a distinção entre verdade contingente e verdade necessária. Cai assim por terra a segunda objecção de Frede contra a interpretação modal de T3 que defendo. ${ }^{25}$

Richard Gaskin é um dos comentadores que mais se aproxima da interpretação modal de T3. No entanto, a sua leitura da passagem não é constante; e, mesmo quando está mais próxima, não coincide exactamente com a que proponho. Gaskin começa por afirmar que, em T3, Aristóteles desvaloriza a distinção entre o "nível ontológico" e o "nível linguístico"26 e autoriza o "movimento livre" de um para o outro. ${ }^{27}$ Numa formulação alternativa, diz que Aristóteles afirma em T3 uma "equivalência geral" entre o discurso no "modo material" (i.e., o discurso sobre as coisas) e o discurso no "modo formal" (i.e., o discurso sobre a linguagem). ${ }^{28} \mathrm{~A}$ ideia parece ser a de que tudo o que se pode dizer num desses "modos" pode também dizer-se no outro "modo". Noutra formulação, percebe-se finalmente que o conceito de verdade desempenha um papel fundamental nessa equivalência: Gaskin diz que, em T3, Aristóteles afirma "a convertibilidade entre os factos e a verdade", a qual consiste numa equivalência lógica entre " $p$ " e "É verdade dizer que $p " .{ }^{29}$ Em todos estes comentários, Gaskin parece querer ver em T3 uma antecipação das ideias que costumamos associar às concepções da verdade como "redundância" (Ramsey) e "descitação" (Quine), nomeadamente, uma antecipação

\footnotetext{
${ }^{25}$ Gaskin 1995, p. 20, n. 9, e Crivelli 2004, p. 215, n. 62, também rejeitam a objecção de D. Frede à interpretação modal de T3.

${ }^{26}$ Gaskin 1995, p. 47, n. 37.

${ }^{27}$ Gaskin 1995, p. 58, n. 14.

${ }^{28}$ Gaskin 1995, p. 168.

${ }^{29}$ Gaskin 1995, p. 86, n. 20, e p. 89.
} 
do princípio segundo o qual afirmar que uma frase é verdadeira é o mesmo que afirmar essa frase. O problema desta leitura é que ela perde de vista o aspecto principal de T3, que é a modalidade. Aristóteles não está aí interessado em afirmar uma identidade entre conteúdos, nem sequer uma equivalência geral entre os "enunciados" e as "coisas". Antes, ele equipara a modalidade que associamos aos enunciados com a modalidade que associamos às coisas. Gaskin aproxima-se desta leitura uma única vez, quando diz que em T3 Aristóteles quer dizer que "as declarações acerca das coisas derivam a sua modalidade da modalidade das coisas". ${ }^{30}$ Ainda assim, este comentário merece dois reparos. Em primeiro lugar, embora seja compreensível e concordante com a tendência realista do pensamento aristotélico, a ideia de "derivação", e a direcção das coisas para as declarações, não se encontra em T3 - que diz apenas que a modalidade é a mesma em ambos os casos. Em segundo lugar, ao sublinhar finalmente o aspecto fundamental da modalidade, Gaskin esquece-se da verdade. É que Aristóteles fala em T3, não em geral da modalidade das declarações, mas, especificamente, da modalidade da sua verdade - é o modo como as declarações são verdadeiras (a saber: necessariamente verdadeiras ou contingentemente verdadeiras) que é, segundo ele, idêntico ao modo como as coisas são (a saber: necessariamente tais e tais ou contingentemente tais e tais). A ideia de Aristóteles é simples, mas, como se pode ver, os seus comentadores perdem-na facilmente.

Paolo Crivelli, no seu amplo estudo da concepção aristotélica da verdade, dedica uma secção à interpretação de $\mathrm{T} 3$, que intitula "A equimodalidade da verdade das asserções e dos estados de coisas". ${ }^{31}$ Como o título indica, para Crivelli é muito claro que o princípio afirmado por Aristóteles em T3 é um princípio de equimodalidade, quer dizer, um princípio que equaciona uma modalidade no plano do dizer com uma modalidade no plano do ser. Crivelli considera que, em T3 como em muitos outros lugares, Aristóteles usa a palavra "pragmata" como um termo técnico para referir estados de coisas e pressupõe a ideia de que a verdade e a falsidade também se atribuem a estados de coisas. Por conseguinte, na sua leitura, Aristóteles estaria a afirmar que as asserções (ou declarações) são verdadeiras com uma modalidade que é idêntica àquela com que os estados de coisas correspondentes são verdadeiros.

\footnotetext{
${ }^{30}$ Gaskin 1995 , p. 89 , n. 32: “... statements about things derive their modality from the modality of the things".

${ }^{31}$ Crivelli 2004, pp. 214-216.
} 
A questão de saber se Aristóteles dispunha da noção de estado de coisas e se admitia a existência de estados de coisas (e, se sim, de que tipos de estados de coisas admitia ele a existência) é uma questão complexa, que aqui não poderei aprofundar devidamente. Creio que Crivelli apresenta evidência textual suficientemente forte para tornar bastante plausível que Aristóteles admitia a existência de estados de coisas (verdadeiros e falsos, ou actuais e não-actuais, ou estados de coisas que obtêm e estados de coisas que não obtêm). ${ }^{32}$ Já a alegação de que "pragmata" em 19a33 se refere a estados de coisas, essa parece-me muito especulativa e bastante forçada. Penso que se pode entender bem a passagem tomando "pragmata" com o sentido corrente de "coisas". Obviamente, Aristóteles não atribui modalidades a indivíduos ou a espécies, mas sim ao seu ser (ou não ser) desta ou daquela maneira. Por isso mesmo, no essencial, concordo com este aspecto da leitura de Crivelli, embora prefira uma formulação diferente e mais simples: onde Crivelli diz que o estado de coisas de $A$ ser $B$ é necessariamente verdadeiro, ou que obtém necessariamente, eu prefiro dizer simplesmente que $A$ é necessariamente $B$. E é essa a "modalidade das coisas" - o seu modo de ser aquilo que são - que Aristóteles equaciona com a modalidade com que os enunciados são verdadeiros.

Surpreendentemente, no entanto, Crivelli considera que o princípio de equimodalidade afirmado por Aristóteles em T3 é um princípio com aplicação muito restrita, que diria apenas respeito a "asserções afirmativas com o verbo no presente". ${ }^{33}$ Porquê esta restrição? Parece-me evidente que não há nada no texto que a justifique. A formulação dada por Aristóteles ao princípio é completamente geral, parecendo estenderse a todo e qualquer enunciado declarativo. Além disso, nas linhas precedentes, Aristóteles deu exemplos que eram acerca do futuro e que eram afirmativos e negativos. Acresce ainda que, se tenho razão na leitura que proponho, então Aristóteles invoca aqui a equimodalidade para esclarecer como deve ser entendida a necessidade que ocorre na RPC, especialmente quando esta regra é aplicada a declarações contraditórias acerca do futuro. A relevância da equimodalidade perder-se-ia por completo, se ela se aplicasse apenas a declarações afirmativas acerca do presente. Mas Crivelli é defensor da interpretação tradicional e pretende promover a ideia de que Aristóteles rejeita a

\footnotetext{
${ }^{32}$ Cf. Crivelli 2004, pp. 46-62.

${ }^{33}$ Crivelli 2004, p. 215: "Aristotle's claim at 19 a33 can [...] be plausibly taken to be that the modality with which a present-tense affirmative assertion is true is the same as the modality with which the corresponding state of affairs is true" (o itálico é meu).
} 
bivalência para declarações acerca de futuros contingentes - e, em última análise, é isso que explica a sua resistência a aplicar o princípio de equimodalidade a estas declarações.

Crivelli justifica a restrição da equimodalidade a declarações afirmativas e acerca do presente dizendo que Aristóteles não admite a existência de estados de coisas negativos e, por isso, provavelmente também não admite a existência de estados de coisas "acerca do futuro". ${ }^{34}$ A ligação entre as duas coisas escapa-me. Não vejo nenhuma razão imediata para que alguém que rejeita estados de coisas negativos deva rejeitar também estados de coisas "acerca do futuro", mesmo que afirmativos. Além disso, penso que Aristóteles não rejeita nenhum destes tipos de estados de coisas. No capítulo 10 das Categorias, ele afirma que o modo de oposição que há entre uma afirmação e a negação contraditória é o mesmo que há entre "as coisas que subjazem" aos dois enunciados, dando como exemplos dessas coisas "subjacentes" o ele estar sentado e o ele não estar sentado ${ }^{35}$ - o que parece ser um testemunho bastante claro de que reconhece a existência de estados de coisas afirmativos e negativos. ${ }^{36}$ Quanto aos estados de coisas "acerca do futuro", penso que há vários exemplos deles no Int. 9. Um deles é o exemplo do manto. Aristóteles diz que o manto para que aponta "não irá ser cortado, mas gastar-se-á antes" (19a13-14). É possível que ao dizê-lo esteja a fazer, não uma afirmação, mas uma suposição (embora pudesse também tratar-se da expressão de uma crença). Se Aristóteles dispunha da noção de estado de coisas, então é provável que analisasse esse acto de suposição como uma relação com um estado de coisas. A explicação seria a seguinte: há dois estados de coisas contraditórios, o estado de coisas de este manto ir ser cortado e o estado de coisas de este manto não ir ser cortado. Suponhamos que o segundo obtém, enquanto o primeiro não obtém. Ainda assim, seria possível que o contrário fosse o caso, isto é, que o primeiro obtivesse e o segundo não. Poderia dar-se uma explicação semelhante para o exemplo da batalha naval. Aristóteles diz que necessariamente amanhã haverá uma batalha ou amanhã não haverá uma batalha. Provavelmente, ele analisaria o exemplo considerando que há dois estados de coisas contraditórios - o de ir haver uma batalha amanhã e o de não ir

${ }^{34}$ Crivelli 2004, p. 215: "Aristotle believes that there are no 'negative' states of affairs corresponding to negative assertions [...]. He is therefore likely to believe that there are no "futuretense' states of affairs corresponding to future-tense assertions [...]."

${ }^{35}$ Cf. Cat. 12b6-15.

${ }^{36}$ Crivelli concorda, mas alega que houve uma evolução no pensamento de Aristóteles que o levou à rejeição dos estados de coisas negativos na Metafísica. Note-se, porém, que a evidência aduzida dessa rejeição na Metafísica é muito fraca - apenas um silêncio onde se poderia esperar (nomeadamente, em 1024b17-25) que algo fosse dito sobre tais estados de coisas (cf. pp. 49-50). 
haver uma batalha amanhã - e que é impossível que nenhum deles obtenha. Uma terceira evidência do reconhecimento de estados de coisas "acerca do futuro" no Int. 9 é a passagem, ainda na primeira parte do capítulo, em que se diz: "E não faz nenhuma diferença se alguém fez ou não fez as declarações contraditórias. Pois é evidente que é assim que as próprias coisas são, mesmo que não tenha havido uma pessoa a afirmá-lo e outra a negá-lo. Pois não é por causa do afirmar ou negar que será ou não será, nem há mais de dez mil anos, nem em outro tempo qualquer. Portanto, se durante todo o tempo as coisas eram de um modo tal que ou uma declaração ou a outra era verdadeira, então ...” (18b36-19a2). Se Aristóteles dispunha da noção de estado de coisas, então é provável que ele deva ser aqui interpretado como estando a desvalorizar a ocorrência efectiva das declarações e a enfatizar a importância da existência - independente dessas declarações - dos estados de coisas correspondentes ${ }^{37}$, um dos quais obtém, não só agora, mas desde sempre. Se "não é por causa do afirmar ou negar que será ou não será", isso significa que há, na realidade, um será ou não será, que é independente de haver ou não alguém a pensá-lo ou a dizê-lo. Esse será e esse não será são entidades “subjacentes”, que se opõem exactamente da mesma maneira que se oporiam a afirmação e a negação, caso estas fossem feitas. ${ }^{38}$ Concluo, então, que a sugestão de que Aristóteles reconhecia em geral a existência de estados de coisas, mas não admitia a existência de estados de coisas "acerca do futuro" carece de fundamento. Desse modo, cai por terra a razão avançada por Crivelli para não aplicar o princípio de equimodalidade às declarações acerca do futuro.

\section{$\S 5$. Verdades Contingentes acerca do Futuro}

O fatalista, com o seu argumento, pretende usar a RPC, aplicada às declarações acerca do futuro, para inferir que tudo é necessário. Aristóteles rejeita esta conclusão, pois toma como evidente que há coisas contingentes - umas que são fortuitas e outras que são

\footnotetext{
${ }^{37}$ Esta passagem coloca especiais dificuldades a alguém que, como Crivelli, pensa que Aristóteles usa "pragmata" como termo técnico para estados de coisas. Pois, em 18b37-38, ele diz dêlon gar hoti houtôs echei ta pragmata ("pois é evidente que é assim que os [estados de coisas] são").

${ }^{38}$ Aristóteles explicita qual é essa maneira de oposição em Cat. 13a37-b3: "É evidente que as coisas que se opõem como afirmação e negação não se opõem de nenhuma das maneiras acabadas de mencionar; pois somente nestas é necessário que sempre uma delas seja verdadeira e a outra falsa." Trata-se, é claro, de mais uma formulação da RPC. À luz do que foi dito em 12b6-15, devemos entender que a condição "sempre uma delas verdadeira e a outra falsa" se aplica também aos estados de coisas contraditórios. O facto de a RPC valer tanto para declarações como para estados de coisas reforça muito a ideia de que deva haver equimodalidade entre os dois planos.
} 
regulares. Qual é então o erro do argumento fatalista? O argumento pode parecer convincente por causa da necessidade que ocorre na RPC, quando nela se diz que é necessário que a afirmação ou a negação seja verdadeira. Mas as atribuições de necessidade devem ser entendidas de maneira cautelosa, pois há um risco de sermos iludidos por diferenças de âmbito. Um exemplo claro e muito significativo de tais diferenças é dado pela lei do terceiro excluído. Considere-se uma batalha naval. Necessariamente, amanhã haverá uma batalha naval ou amanhã não haverá uma batalha naval. Mas, neste caso, não podemos "dividir" e distribuir a necessidade pelos membros da disjunção. E no caso da RPC? Se fizéssemos na RPC a operação de "dividir", diríamos que ou é necessário que a afirmação seja verdadeira ou é necessário que a negação seja verdadeira. Mas, quando se trata de coisas contingentes, isso não é correcto. Pois a modalidade com que as declarações são verdadeiras é a mesma que a modalidade com que as coisas são como são.

Nas linhas que se seguem a T3, Aristóteles usa a equimodalidade e a existência de coisas contingentes - dos dois tipos - para justificar que, qualquer que seja a verdade a respeito dos futuros contingentes, será sempre uma verdade contingente; e, por isso, a necessidade tem de ser entendida na RPC também de maneira "não-dividida".

T5

[a] Por conseguinte, uma vez que os enunciados são verdadeiros da mesma maneira como as próprias coisas são, é claro que, sempre que estas são de modo a admitirem os contrários de maneira casual, o mesmo se aplica necessariamente também à contradição. [b] Isso acontece com as coisas que nem são sempre assim nem são sempre não-assim. [c] Pois, com estas, é necessário que uma parte ou outra da contradição seja verdadeira ou falsa; porém, não tem de ser esta parte, ou aquela parte, mas sim de maneira casual; $[d]$ e mesmo que uma seja mais verdadeira do que a outra, isso não implica que tenha de ser verdadeira, ou falsa. (19a32-39)

A estrutura geral de T5 é a seguinte. Em [a], Aristóteles formula o princípio de equimodalidade e extrai a sua consequência natural: a contingência das coisas sobre as quais são feitas as declarações contraditórias deve reflectir-se numa contingência correspondente quanto à maneira de uma das declarações ser verdadeira. A RCP, e a necessidade que nela ocorre, deve ser entendida de maneira a salvaguardar essa contingência do ser verdadeiro. Em $[b]$, Aristóteles dirige a sua atenção às coisas nãonecessárias, com o propósito de examinar como se aplica a RCP às declarações a seu respeito. Essas coisas são de dois tipos. Em $[c]$ considera as coisas contingentes fortuitas; e em $[d]$ considera as coisas contingentes regulares. Em ambos os casos, verifica-se que 
tem de haver uma declaração verdadeira (no par contraditório), mas nenhuma das declarações tem de ser verdadeira.

As partes finais, $[c]$ e $[d]$, são as mais importantes. Em $[c]$, Aristóteles foca a sua atenção nas declarações a respeito das coisas fortuitas, do género daquelas que foi dando como exemplo ao longo do capítulo (o homem ir ser branco, o manto ir ser cortado ou ir haver uma batalha), e faz duas afirmações fundamentais. Em primeiro lugar, afirma que a RPC se aplica a estas declarações: "com estas [coisas], é necessário que uma parte ou outra da contradição seja verdadeira ou falsa" (19a36-37) ${ }^{39}$ Em segundo lugar, afirma que, tal como com a lei do terceiro excluído, também neste caso não é legítimo "dividir": "porém, não tem de ser esta parte ou aquela parte, mas sim de maneira casual" (19a3738). Podemos encontrar aqui a resposta à primeira objecção de D. Frede contra a interpretação modal de T3, que referimos antes e cujo exame adiámos. Contra a presença em T3 de uma modalização da verdade, Frede alegava que a distinção entre verdade contingente e verdade necessária não é aplicada por Aristóteles nas linhas que se seguem a T3. Ora, como podemos agora ver, efectivamente, essa distinção é aqui aplicada, ainda que de modo implícito. Pois se, na RPC a respeito das coisas fortuitas, fosse legítimo “dividir", uma das declarações seria necessariamente verdadeira. Precisamente, porque as verdades acerca de tais coisas são elas próprias verdades contingentes (em consonância com o princípio de equimodalidade), não podemos "dividir" quando expressamos a necessidade na RPC. Embora Aristóteles não o diga, é provável que ele pense que, quando a RPC diz respeito a declarações acerca de coisas necessárias (que são "sempre assim" ou "sempre não-assim”), é legítimo "dividir", quer dizer, não só tem de haver uma declaração verdadeira, como há mesmo uma declaração que tem de ser verdadeira.

É muito significativo que, para expressar esta diferença entre "tem de haver uma declaração verdadeira" e "há uma declaração que tem de ser verdadeira", Aristóteles recorra aqui à fórmula "não tem de ser esta parte, ou aquela parte, mas sim de maneira casual". Pois essa fórmula é muito semelhante a uma fórmula usada nas Categorias 10

\footnotetext{
${ }^{39}$ A afirmação da RPC que ocorre em T5-[c] (19a36-38) constitui um enorme obstáculo para a interpretação tradicional e, em geral, para quem quer que considere que Aristóteles, no Int. 9, admite uma nova excepção à RPC, a qual implicaria também (uma vez que as opções "ambas verdadeiras" e "ambas falsas" foram afastadas, cf. supra n. 4) uma excepção ao princípio da bivalência. É em T5-[d] (19a38-39) que os defensores dessa leitura encontram a rejeição da bivalência. Mas T5- $[d]$ diz apenas respeito às coisas regulares, e não invalida nada do que já foi afirmado em T5-[c]. Como bem nota Gail Fine (1985, p. 35): "if Aristotle is rejecting bivalence here [i.e., em T5- $(d)$ ], he is rejecting it only for usual events; the clause does not apply back to chance events. This is an odd result." Cf., no mesmo sentido, Whitaker 1996, p. 123.
} 
para expressar uma diferença semelhante. Valerá a pena fazermos essa comparação. ${ }^{40}$ Nesse capítulo das Categorias, a dado passo (de 11b38 em diante), Aristóteles pretende distinguir dois tipos de contrários - os contrários sem intermédio (como a doença e a saúde) e os contrários com intermédio (como o quente e o frio, o branco e o negro ou o bom e o mau). Para caracterizar a diferença em causa, Aristóteles encontra uma regra que podemos formular da seguinte maneira: [C] Se $A$ e $B$ são contrários e $x$ é uma coisa no seu campo de aplicação (ou uma coisa “capaz de os receber"), então $A$ e $B$ têm intermédio se e somente se não é necessário que um dos dois $-A$ ou $B$ - pertença a $x$. Em seguida (em 12b37-38), Aristóteles dá-se conta de que [C] tem contra-exemplos, como este: o quente e o frio são contrários com intermédio, mas há coisas no seu campo de aplicação - por exemplo, o fogo - que são tais que é necessário que um dos dois lhe pertença. Pois o fogo é necessariamente quente (tal como a neve é necessariamente branca). Ao procurar rever a regra $[\mathrm{C}]$ para acomodar estes contra-exemplos, Aristóteles apercebe-se de que afirmações com a forma "É necessário que $A$ ou $B$ pertença a $x$ " podem ser entendidas de duas maneiras. Especialmente interessante é o modo como expressa essa diferença. Num caso como o do quente-frio relativamente ao fogo, diz que é "definidamente um deles" que tem de pertencer ao fogo (aphôrismenôs anankaion thateron hyparchein, 12b39). Enquanto que, num caso como o da visão-cegueira relativamente a um homem adulto, diz que é necessário que uma ou a outra lhe pertença, mas é "não definidamente uma das duas coisas, mas de maneira casual" (ouk aphôrismenôs thateron, all' hopoteron etychen, 13a11). É claro que a diferença em causa tem a ver, uma vez mais, com o âmbito da necessidade. Usando terminologia moderna, diríamos que, no primeiro tipo de casos, a necessidade pode ser afirmada com âmbito tanto longo como curto (é legítimo “dividir”), enquanto que, no segundo tipo de casos, a necessidade pode ser afirmada com âmbito longo apenas (não é legítimo “dividir”). Ora, é uma diferença semelhante que Aristóteles pretende captar no Int. 9, em 19a36-38. E embora não use a expressão “definidamente uma delas" (aphôrismenôs thateron), emprega "de maneira casual” (hopoteron etychen) exactamente com o mesmo intuito. A intenção parece clara: Aristóteles pretende dizer que, a respeito de coisas futuras contingentes fortuitas (como ir haver uma batalha naval ou este manto ir ser cortado), dado um par de declarações contraditórias a seu respeito, é

\footnotetext{
${ }^{40} \mathrm{O}$ modo como Aristóteles usa hopoteron etychen em Int. 9, 19a38, é notoriamente semelhante ao modo como usa essa mesma expressão em Cat. 10, 12b40, 13a3, 13a11 e 13a12-13. Cf. Hintikka 1973, p. 164, n. 23; Santos 2016, p. 107, n. 165.
} 
necessário que uma delas seja verdadeira, mas nenhum delas é necessariamente verdadeira.

Por fim, em $[d]$, Aristóteles acrescenta: "e mesmo que uma seja mais verdadeira do que a outra, isso não implica que tenha de ser verdadeira, ou falsa" (19a38-39). Com a possibilidade de que seja "uma mais verdadeira do que a outra", já sabemos, à luz do que vimos a respeito de T1, que Aristóteles se refere ao segundo tipo de coisas contingentes, a saber, aquelas que "são na maior parte dos casos mais de uma maneira do que de outra" (19a20-21) - como, por exemplo, a ingestão de hidromel, que faz baixar a febre na maior parte dos casos. Dada essa tendência natural, e a regularidade que ela origina, uma das declarações contraditórias é verdadeira em mais casos ou mais frequentemente do que a outra. E Aristóteles limita-se a repetir, agora no "modo formal" (em 19a39), aquilo que já tinha dito, no "modo material", em 19a21-22: apesar dessa tendência e regularidade, de cada vez que uma dessas declarações é verdadeira (ou falsa), ela é apenas contingentemente verdadeira (ou falsa).

Os defensores da interpretação tradicional pretendem ler em $[d]$ uma negação da bivalência, traduzindo essas linhas como: “ou [é necessário] que uma seja mais verdadeira do que a outra, mas não é necessário que seja verdadeira, ou falsa, já" ${ }^{41}$ Embora seja linguisticamente legítima, há pelo menos três razões contra esta leitura da passagem. Em primeiro lugar, rejeitar a bivalência a respeito desta classe de declarações implicaria também rejeitar a RPC a respeito delas ${ }^{42}$, mas Aristóteles não rejeita a RPC a respeito das declarações acerca do futuro. Como vimos, em T1, ele diz que a RPC se aplica às coisas fortuitas e às coisas regulares de maneiras diferentes, pressupondo assim que ela se aplica a ambas. Em segundo lugar, se Aristóteles rejeitasse a bivalência e a RPC em 19a39, essa rejeição valeria apenas para as declarações sobre as coisas regulares, pois em 19a36-37 ele afirmou que a RPC se aplica às declarações sobre as coisas fortuitas. Desse modo, Aristóteles teria apenas uma resposta muito parcial para dar ao argumento fatalista, a qual deixaria de fora precisamente o tipo de casos que o fatalista (querendo provar que nada acontece por acaso ou de maneira casual) tem principalmente em vista. ${ }^{43}$ Por último, a leitura sugerida ignora o facto de que, na sequência argumentativa do texto, $[c]$ e $[d]$

${ }^{41}$ O advérbio êdê (em 19a39) pode ter um sentido temporal, significando "já" ou "desde já", e pode também ter um sentido lógico, significando "por causa disso". Cf. Anscombe 1956, p. 8; Fine 1984, p. 35; Judson 1988, p. 17, n. 8; Crivelli 2004, p. 223, n. 79.

${ }^{42}$ A RPC implica o princípio da bivalência. Cf. Jones 2010, p. 55.

${ }^{43}$ Cf., supra, n. 39. 
dependem de $[b]$ e de $[a]$. Essa dependência significa que o objectivo de toda a passagem é mostrar que, de acordo com a equimodalidade entre verdades e factos, afirmações e negações acerca de coisas contingentes - fortuitas ou regulares - são sempre, se verdadeiras, apenas contingentemente verdadeiras e, se falsas, apenas contingentemente falsas - e que isso é consistente com a necessidade de que uma delas seja verdadeira, incluída na RPC.

\section{§6. Conclusão}

Procurei, neste ensaio, alcançar dois objectivos. O primeiro foi mostrar que a distinção aristotélica entre as coisas que acontecem de maneira casual ou sem regra e as coisas que acontecem na maior parte dos casos de uma certa maneira, conhecida de outros textos, está também presente no Int. 9 e desempenha um papel importante na sequência argumentativa do capítulo. A este respeito, pudemos observar um facto interessante. $\mathrm{O}$ Int. 9 divide-se em duas partes principais: na primeira (até 19a6), Aristóteles expõe o argumento fatalista tentando colocar-se no ponto de vista do próprio fatalista; na segunda (a partir de 19a7), Aristóteles faz a sua crítica ao argumento. Ora, é notório e significativo que aquela distinção aristotélica está quase ausente na primeira parte (havendo talvez apenas uma pequena alusão a ela, muito pouco explícita, em 18b8-9). O argumento é inicialmente apresentado como conduzindo à conclusão de que tudo acontece necessariamente e, por isso, não há nada que aconteça por acaso ou de maneira casual. Mas na segunda parte, quando diz o que pensa e nega a tese fatalista, aí a distinção é claramente introduzida, uma vez que Aristóteles considera que há muitas coisas contingentes e que elas são daqueles dois tipos. Aristóteles poderá ter pensado que o fatalismo eliminaria não apenas a categoria do fortuito, mas também essa outra categoria, central na sua concepção da natureza e da ciência, que é a das coisas que são de uma maneira, não sempre e necessariamente, mas na maior parte dos casos (hôs epi to poly). Também muito importante para a compreensão da resposta de Aristóteles ao fatalista é observar que é a esta distinção que ele volta na passagem final, em 19a35-39. A comparação daquilo que Aristóteles diz nessas duas vezes que menciona as coisas regulares (ou que são de uma maneira na maior parte dos casos) é extremamente instrutiva: na primeira vez, nota que elas não são necessárias (19a21-22); na segunda, sublinha que as verdades a seu respeito não são verdades necessárias (19a39). 
O segundo objectivo do ensaio foi analisar o princípio de equimodalidade formulado em 19a33 e mostrar que ele constitui a base principal da resposta de Aristóteles ao fatalista. De acordo com esse princípio, a modalidade de uma verdade está sempre alinhada com a modalidade do facto que lhe corresponde: se uma coisa é contingentemente de uma certa maneira, então o enunciado declarativo que diz que ela é dessa maneira é contingentemente verdadeiro. Isto aplica-se também ao futuro: por exemplo, se amanhã não vai haver nenhuma batalha naval, mas seria possível que houvesse uma, então o enunciado que diz que amanhã não haverá nenhuma batalha naval é verdadeiro, mas poderia ser falso. Na interpretação que defendi, Aristóteles vê neste princípio o elemento decisivo para responder ao fatalista. Infelizmente, ele não explicita tão completamente quanto poderíamos desejar as consequências do princípio para a presente discussão. $\mathrm{O}$ aspecto em que se concentra é o das suas consequências para a maneira como devemos entender a RPC, quando esta se aplica a coisas futuras e contingentes (de qualquer dos dois tipos). De acordo com a regra, sempre que um par de declarações contraditórias são feitas acerca de tais coisas, tem de haver uma delas que é verdadeira (é impossível que nenhuma delas seja verdadeira). Mas daí não se segue que há uma delas que tem de ser verdadeira. Aliás, isso não só não se segue, como não é efectivamente o caso, dado o requisito de equimodalidade. A declaração verdadeira, seja ela qual for (mas tem de haver uma), será apenas contingentemente verdadeira. $\mathrm{O}$ verdadeiro e o falso poderiam distribuir-se pelos membros do par contraditório de maneira inversa àquela como efectivamente estão distribuídos.

Penso que, com a compreensão que aqui alcançámos destes dois aspectos do Int. 9, a plausibilidade da interpretação bivalente do capítulo sai grandemente reforçada. Todavia, para se proceder a uma defesa completa dessa interpretação, outras coisas serão ainda necessárias. Desde logo, será preciso examinar outras partes do capítulo, que aqui não considerei. Além disso, dever-se-á procurar responder à questão que o leitor moderno, conhecedor da discussão posterior do problema, naturalmente se coloca, e que é a seguinte: se a crítica de Aristóteles ao argumento fatalista é esta que descrevi, então como responderia ele à objecção segundo a qual a admissão de que existem agora verdades acerca do futuro, mesmo que essas verdades sejam contingentes, é suficiente para gerar a consequência fatalista de que, como não podemos mudar essas verdades, então não há nada que possamos fazer daqui em diante para evitar que as coisas venham a ser como 
essas verdades dizem que irão ser? Pois é por causa desta objecção ${ }^{44}$, e porque reconhecem a sua força, que muitos se sentem atraídos pela solução não-bivalente que a interpretação tradicional atribui a Aristóteles. Mas estas são tarefas para trabalho futuro. ${ }^{45}$

Ricardo Santos

LanCog, Centro de Filosofia da Universidade de Lisboa

\section{Referências Bibliográficas}

Anscombe, G. E. M. 1956. “Aristotle and the Sea Battle”, Mind 65, pp. 1-15.

Bäck, Allan. 1992. "Sailing through the Sea Battle", Ancient Philosophy 12, pp. 133-151.

Byrd, Jeremy. 2010. "The Necessity of Tomorrow's Sea Battle", The Southern Journal of Philosophy 48, pp. 160-176.

Crivelli, Paolo. 2004. Aristotle on Truth. Cambridge: Cambridge University Press.

Fine, Gail. 1984. "Truth and Necessity in De Interpretatione 9", History of Philosophy Quarterly 1, pp. 23-47.

Frede, Dorothea. 1985. "The Sea-Battle Reconsidered: a Defence of the Traditional Interpretation", Oxford Studies in Ancient Philosophy 3, pp. 31-87.

Gaskin, Ricard. 1995. The Sea Battle and the Master Argument. Berlin: Walter de Gruyter.

Hintikka, Jaakko. 1973. Time and Necessity. Oxford: Clarendon Press.

Jones, Russell E. 2010. "Truth and Contradiction in Aristotle's De Interpretatione 6-9”, Phronesis 55 , pp. 26-67.

Judson, Lindsay. 1988. "La Bataille Navale d'Aujourd'hui: De Interpretatione 9", Revue de Philosophie Ancienne 6, pp. 5-37.

Judson, Lindsay. 1991. "Chance and 'Always or For the Most Part' in Aristotle", in L. Judson (ed.), Aristotle’s Physics. Oxford: Clarendon Press, pp. 73-99.

Łukasiewicz, Jan. 1970. “On Determinism”, in L. Borkowski (ed.), Jan Łukasiewicz: Selected Works. Amsterdam: North-Holland Publishing Company, pp. 110-128.

\footnotetext{
${ }^{44}$ Parece-me que a objecção que formulo no texto coincide com aquilo a que Byrd (2010, p. 163) chama "the Inference Problem". Byrd pensa que Aristóteles reconheceu a força do argumento contido na objecção e procura encontrar as razões que o terão conduzido a isso. Eu duvido que Aristóteles tenha reconhecido essa força.

${ }^{45}$ Apresentei versões preparatórias deste trabalho na Universidade Estadual de Campinas, na Universidade de La Laguna, na Universidade de Évora, na Universidade do Minho, na Universidade de Genève, na Universidade Federal do Rio de Janeiro e na Universidade de Lisboa. Agradeço aos participantes nesses encontros a discussão de vários pontos, a qual me permitiu afinar muitas ideias.
} 
Mignucci, Mario. 1981. "Hôs epi to poly et Nécessaire dans la Conception Aristotélicienne de la Science", in E. Berti (ed.), Aristotle on Science: the Posterior Analytics. Padova: Antenore, pp. 173-203.

Santos, Ricardo. 2016. Aristóteles: Categorias e Da Interpretação. Lisboa: Imprensa Nacional Casa da Moeda.

Striker, Gisela. 2009. Aristotle: Prior Analytics, Book I. Oxford: Clarendon Press.

van Inwagen, Peter. 1983. An Essay on Free Will. Oxford: Clarendon Press.

van Rijen, Jeroen. 1989. Aspects of Aristotle's Logic of Modalities. Dordrecht: Kluwer Academic Publishers.

Whitaker, C. W. A. 1996. Aristotle's De Interpretatione. Oxford: Clarendon Press. 